\title{
ASSOSIATION BETWEEN COGNITIVE LEVEL, INDEPENDENCE IN DAILY LIVING ACTIVITIES, AND DEPRESSION AMONG THE ELDERLY IN A NURSING HOME, SURAKARTA, CENTRAL JAVA
}

\author{
Ninik Nurhidayah, Bhisma Murti, Pancrasia Murdani K \\ Masters Program in Family Medicine, Sebelas Maret University
}

\begin{abstract}
BACKGROUND: Various physical, psychological, and social problems arise in the elderly due to the degenerative process. One of the common problems experienced by the elderly is depression. Increased life expectancy does not seem to balance with quality of life. Quality of life among the elderly does not generally improve with the prolonged life expectency. This study aimed to examine the assosiation between cognitive level, independence in activities of daily living, and depression, among the elderly in a nursing home.

SUBJECT AND METHODS: This was a cross sectional study, conducted in Surakarta, Central Java. A sample of 40 elderly was selected at random from Dharma Bhakti Nursing Home, Surakarta. The dependent variable was deperession. The independent variables included cognitive level and independence in daily living activities. Depression was measured by Geriatric Depression Scale. Cognitive level was measured by Mini Mental Status Examination. Independence in daily living activities was measured by Barthel's Index instrument. The data was analyzed using multiple linear regression model.

RESULTS: Depression in the elderly was negatively associated with cognitive level $(b=-0.26 ; p=0.024)$ and independence in daily living activities $(\mathrm{b}=-0.25 ; \mathrm{p}=0.001)$. Adjusted $\mathrm{R}^{2}=0.42$; overall $\mathrm{p}=0.001$.

CONCLUSION: There are relationships between cognitive level, independence in daily living activities, and depression among the elderly. Depression among the elderly can be minimized by empowering the elderly so as to make them more independent in daily living activities as well as keeping their brain active.
\end{abstract}

Keywords: depression, cognitive, activities of daily living, elderly 